\title{
Youth running consensus statement: minimising risk of injury and illness in youth runners
}

\author{
Brian J Krabak (D) ,' William O Roberts (D) ,' ${ }^{2}$ Adam S Tenforde, ${ }^{3}$ \\ Kathryn E Ackerman (D) , ${ }^{4}$ Paolo Emilio Adami (D) , ${ }^{5}$ Aaron L Baggish, ${ }^{6}$ \\ Michelle Barrack, ${ }^{7}$ John Cianca ${ }^{8}$ Irene Davis, ${ }^{9}$ Pierre D'Hemecourt, ${ }^{4}$ \\ Michael Fredericson, ${ }^{10}$ Joshua T Goldman (1) , ${ }^{11}$ Mark A Harrast, ${ }^{1}$ \\ Bryan C Heiderscheit, ${ }^{12}$ Karsten Hollander (D) , ${ }^{13}$ Emily Kraus (D) , ${ }^{14}$ Anthony Luke, ${ }^{15}$ \\ Emily Miller, ${ }^{11}$ Melissa Moyer, ${ }^{16}$ Mitchell J Rauh, ${ }^{17}$ Brett G Toresdahl, $^{18}$ \\ Meagan M Wasfy ${ }^{6}$
}

- Additional material is published online only. To view, please visit the journal online (http://dx.doi.org/10.1136/ bjsports-2020-102518).

For numbered affiliations see end of article.

Correspondence to Dr Brian J Krabak Rehabilitatiion, Orthopedics and. Sports Medicine, Univesrity of Washington, Seattle, WA 98195, USA; bkrabak@uw.edu

Accepted 4 October 2020 Published Online First 29 October 2020
Check for updates

(C) Author(s) (or their employer(s)) 2021. No commercial re-use. See rights and permissions. Published by BMJ.

To cite: Krabak BJ, Roberts WO, Tenforde AS et al. Br J Sports Med 2021:55:305-318

\section{ABSTRACT}

Despite the worldwide popularity of running as a sport for children, relatively little is known about its impact on injury and illness. Available studies have focused on adolescent athletes, but these findings may not be applicable to preadolescent and pubescent athletes. To date, there are no evidence or consensus-based guidelines identifying risk factors for injury and illness in youth runners, and current recommendations regarding suitable running distances for youth runners at different ages are opinion based. The International Committee Consensus Work Group convened to evaluate the current science, identify knowledge gaps, categorise risk factors for injury/illness and provide recommendations regarding training, nutrition and participation for youth runners.

\section{BACKGROUND}

Running is a popular sport for children throughout the world. Globally, running participation rates for preadolescents and adolescents vary reaching as high as $40 \%$ in some regions of the world. ${ }^{1}$ In the USA, running is the second most common physical activity among girls age $12-15$ years (34.9\%) and boys age $12-15$ years $(33.5 \%) .^{2}$ During the 2018 2019 academic year, 488640 high school (HS) students participated in cross country (219345 girls and 269295 boys) and 1243874 participated in track and field (558970 girls and 684904 boys) in the USA. ${ }^{3}$

With the growth of participation in youth running, there has been an observed increase in the number of running-related injuries. Absolute numbers of running related injuries increased by $34 \%$ from 1994 to 2007 based on a study of 225344 children presenting to US emergency departments; the highest injury rate (45.8 per 100000 US population) occurring in runners aged 12-14 years old compared with other child age groups. ${ }^{4}$ In a study of 405305 preadolescent and adolescents, 25\% of physical education-related injuries were associated with running (1997-2007). ${ }^{5}$ Fortunately, most injuries were minor in nature, involving sprains, strains and apophyseal injuries. More serious injuries, including stress fractures or physeal injuries, were far less common. ${ }^{67}$
Although some sports medicine organisations have focused on youth athletes and youth sport safety guidelines, no specific recommendations have been published for youth running. A panel of experts was assembled to identify key topics related to participation and safety in youth running. The focus of this expert panel was to reduce injury and illness risk for youth runners and promote lifelong health for youth runners. The intended audience includes sports and exercise physicians, other practitioners (eg, nurse practitioners, physician assistants, physiotherapists, athletic trainers) performance professionals (eg, coaches, trainers) who work with youth runners, researchers in the field of youth running and clinical or institutional leaders/administrators who are stakeholders in youth running.

The expert panel identified the following essential tasks to address:

- Identify evidence-based risk factors for injury or illness in the youth runner.

- Describe and establish recommendations for injury and illness risk screening in the youth runner.

- Provide recommendations for adequate nutrition, safe training loads and readiness for youth runners to minimise potential negative impacts of distance running.

\section{METHODS}

The organising committee (BJK, WOR and AST) for this effort began planning for the consensus meetings in July 2018 with six meetings to discuss the scope, topics and timeline for the consensus statement (figure 1). We agreed to define running as an athletic sport based on the following US Track and Field (USATF) disciplines for running (ie, Track \& Field, Cross Country, Mountain Ultra Trail and Road Running). ${ }^{8}$ We did not define a specific distance, instead focusing on the evidence-based research specific to the youth runner. In addition, we agreed to use the USATF terminology to define a youth runner as someone 18 years old or younger. ${ }^{8}$ 'Preadolescent' was used to refer to youth runners aged $\leq 12$ years old and 'adolescent' for youth runners aged 13-18 years old. 


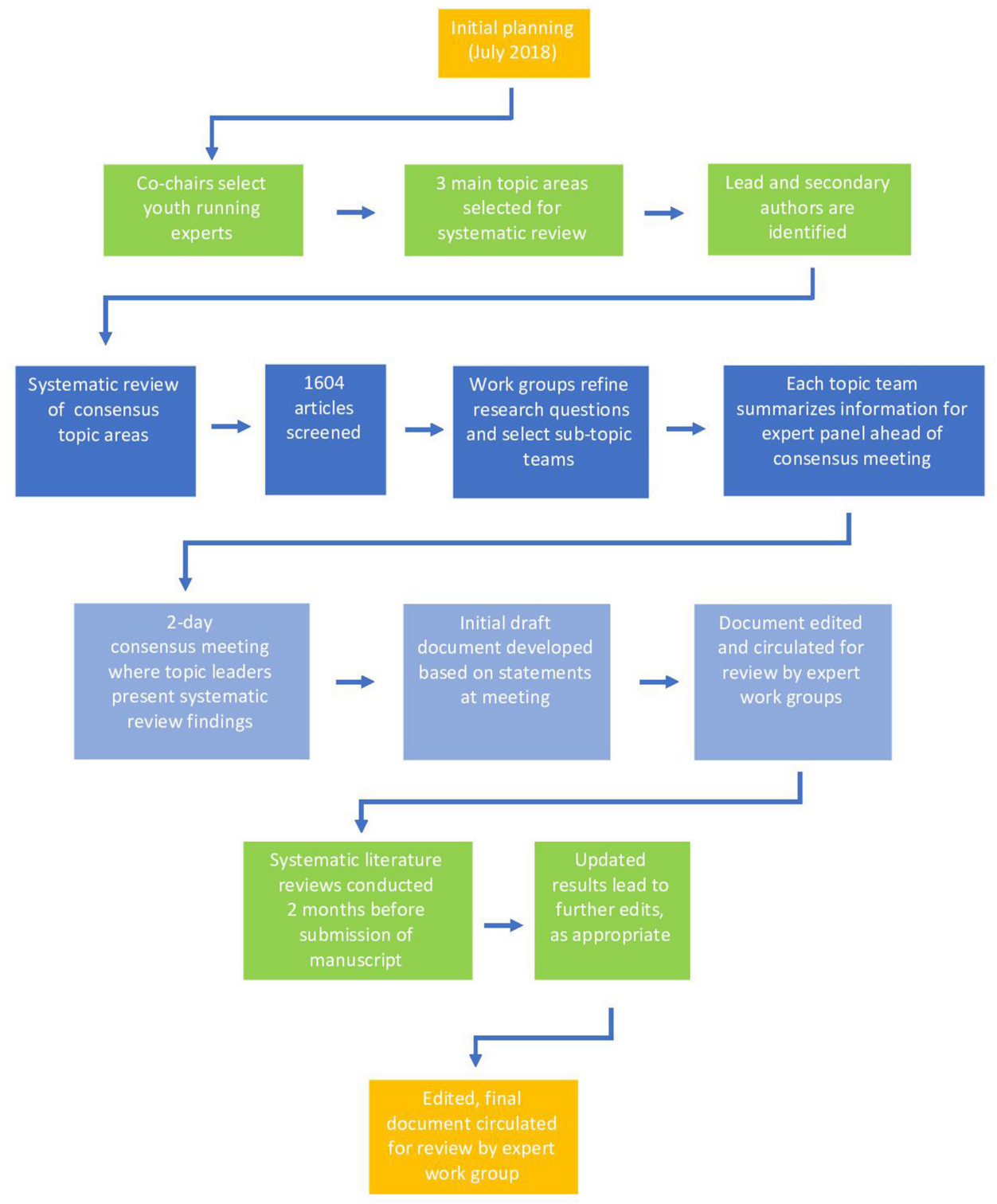

Figure 1 Consensus process for literature review, meeting and publication.

The organising committee identified key leaders and researchers with expertise in youth running injuries based on their clinical and/or scientific contributions to specific topics in youth running. The final working group was composed of 22 individuals from four nations (Brazil, Germany, Italy and the USA). The group included sports medicine specialists from family medicine, paediatrics, physiatry, orthopaedic surgery, cardiology, endocrinology, physical therapy and sports nutrition.

\section{Systematic review}

The organising committee identified three main topic areas for the consensus statement: Injury Risk Factors and Prevention, Factors That May Impact Long Term Health and Appropriateness of Running as a Sport for Children. A lead author from the organising committee was identified to guide development of each main topic, including subcategories and working group experts. Each working group developed a series of questions to address within the topic area and identified knowledge gaps.

A systematic search of the literature was performed with the assistance of an experienced librarian using multiple databases including PubMed, SportDiscus, Scopus and Cochrane. The working groups provided input to ensure all relevant search terms ([young OR youth OR pediatric OR immature OR high school OR child OR adolescent] AND [athlete OR athletes OR sport] AND [run OR running OR runner OR track OR cross-country] AND [injury OR injuries OR pain OR illness]) were included in the initial search strategy. The initial search (1 January 1980-1 May 2019) included all study designs and was limited to the English language. The expert panel screened 1602 published articles, focusing on articles specific to running as a primary sport. Searches were revised by the organising committee and working groups to identify prospective studies for each of the three main topic areas.

- The final literature review used a Preferred Reporting Items for Systematic Reviews and Meta-Analyses protocol ${ }^{9}$ to address topics with prospective published research specific to youth running (Risk Factors and Injury Prevention) (figure 2 and online supplemental material).

- A detailed, narrative review was used to address topics or questions without prospective published research specific to youth running (Factors That May Impact Long Term Health 


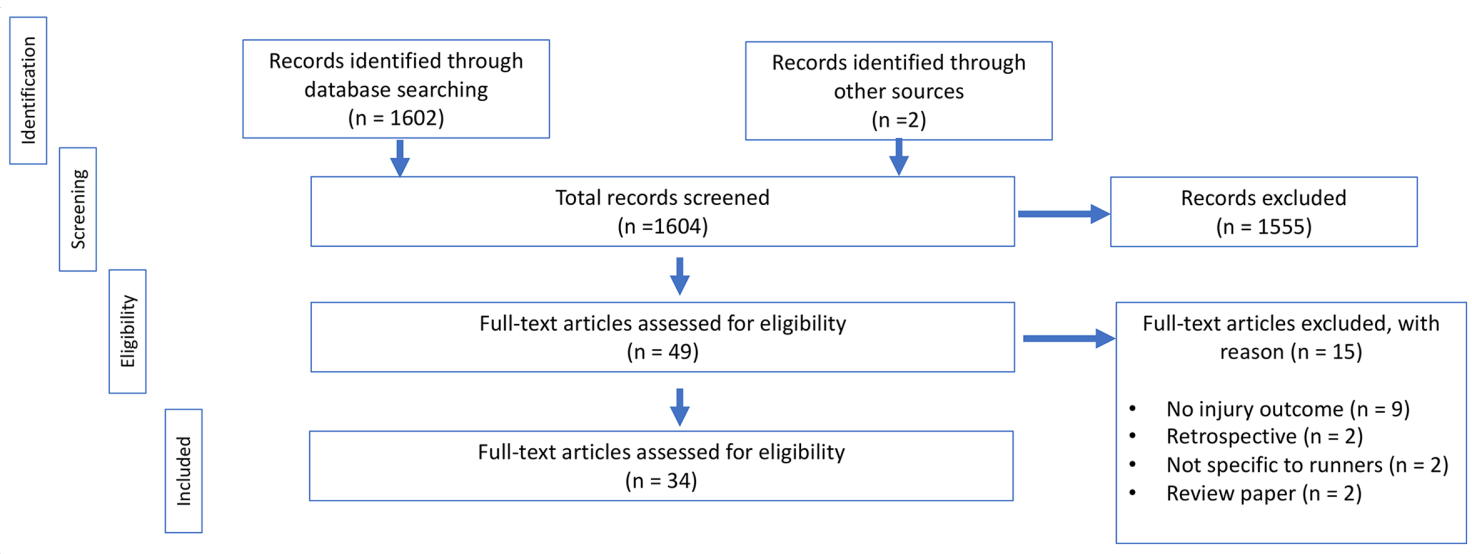

Figure 2 Youth running consensus group PRISMA protocol. PRISMA, Preferred Reporting Items for Systematic Reviews and Meta-Analyses.

and Appropriateness of Running as a Sport for Children), incorporating evidence from older runners or youth sports, as appropriate.

Each working group was tasked with summarising the key information from its review, developing a proposed consensus statement and identifying knowledge gaps. Each key article was assigned a level of evidence rating (1-5) based on the methodological quality of the design. Each working group shared and presented its findings at one of two consensus meetings.

\section{Consensus meetings}

The consensus meetings occurred in-person or through video conferencing on two separate days in Boston, Massachusetts and Orlando, Florida in May 2019. Each meeting followed a similar format of topic leaders presenting their review findings followed by group discussion to develop a final consensus statement. Each consensus statement was graded using the Strength of Recommendation Taxonomy (SORT). A member of the organising committee took notes during the discussion to capture key comments.

\section{Writing the consensus statement}

An initial draft of the consensus statement was crafted by the organising committee members based on the two consensus meetings. Key statements agreed on during the meetings were not changed during the creation of the final document. Systematic literature reviews using the original research strategies were reconducted 2 months prior to submission to ensure inclusion of the most recent literature. The updated search results were provided to the working groups and additional edits made accordingly. The edited document was circulated to the entire expert panel for review, comment and further editing, as appropriate. All members agreed on the final document.

\section{INJURY RISK FACTORS AND PREVENTION}

Decreasing the risk of injury in youth runners requires an understanding of normal child growth and development. The youth runner is especially vulnerable during periods of rapid growth when long bones lengthen more rapidly than the muscle-tendon complex, thereby increasing tensile forces on the muscle-tendonbone transitions. ${ }^{71011}$ Two important factors during this period of growth include peak height velocity (PHV), defined as the maximum rate of growth in height, and rate of deposition of bone mineral content. On average, PHV occurs around age 12 years for girls and age 14 years for boys, but there is variation in the onset range. ${ }^{12}$ Because PHV occurs before peak bone mineralisation rate in both girls and boys, adolescents experience a period of transient bone weakness. ${ }^{12} 13$ These windows of rapid biological change may place the youth runner at risk for injury to the musculoskeletal (MSK) structures (growth plates, apophyses, bones, muscles or tendons). ${ }^{71011}$

Thus, during the transformation from a child to adult, one must consider the various intrinsic factors (eg, height, weight, strength, alignment) and extrinsic factors (eg, training, footwear) that may place the youth athlete at risk for injury. It is with this perspective that the following sections use evidence-based literature to develop consensus statements regarding intrinsic (table 1) and extrinsic (table 2) factors that may impact the risk of injury in the young runner.

\section{Intrinsic factors}

Height, weight and body mass index

Despite our understanding of MSK system changes during growth, there are few studies that have assessed the impact of changing height, weight and body mass index (BMI) on the risk of injury in the youth runner. A prospective study of 421 cross country runners (186 girls, 235 boys), ages 14-18 years, examined the impact of height and weight on injuries during the season. Height and weight were not significantly different between injured (height: $169.7 \pm 8.6 \mathrm{~cm}$, mass: $58.5 \pm 8.0 \mathrm{~kg}$ ) and non-injured athletes $(171.4 \pm 8.5 \mathrm{~cm}, 60.1 \pm 8.5 \mathrm{~kg})$ for either girls or boys $(p=0.16) .{ }^{14}$ Similarly, a study of 230 cross country runners (96 girls, 134 boys), ages 15-18 years, reported no difference in the rate of lower extremity stress fractures in relationship to initial height and weight measurements in both males (height: $172.0 \pm 2.6$ vs $170.4 \pm 5.4$, respectively, $\mathrm{p}>0.05$; weight: $56.6 \pm 6.1$ vs $55.6 \pm 4.8$, respectively, $\mathrm{p}>0.05)$ and females (height: $159.9 \pm 3.8$ vs $56.6 \pm 6.1$, respectively, $\mathrm{p}>0.05$; weight: $48.9 \pm 5.6$ vs $46.3 \pm 4.3$, respectively, $p>0.05$ ) over a 3 -year period. ${ }^{15}$ These studies suggest that height and weight are not associated with increased risk of injury in the adolescent cross country athlete. Further studies are needed to assess how the changes in growth related height and weight impact injury in pre-adolescent runners.

In contrast to height and weight, BMI does appear associated with increased risk of injury in the youth runner. A study of 105 cross-country runners (46 girls, 59 boys), ages $13-18$ years, found runners with a BMI of $20.2-21.6 \mathrm{~kg} / \mathrm{m}^{2}$ were 7.3 times more likely to experience medial tibial stress syndrome than runners with a BMI of $18.8-20.1 \mathrm{~kg} / \mathrm{m}^{2}(\mathrm{OR}=7.3,1.2-43.5$, $\mathrm{p}<0.05) .{ }^{16}$ A prospective study of 748 competitive HS runners (442 girls, 326 boys), ages 13-18 years found girls with a 


\begin{tabular}{|c|c|c|}
\hline Topic & Statement & SORT rating \\
\hline \multicolumn{3}{|l|}{ ALL INJURIES } \\
\hline Sex & $\begin{array}{l}\text { Evidence strongly supports girls are at higher } \\
\text { risk for running related injury and greater } \\
\text { time loss from injury than boys. }\end{array}$ & A \\
\hline Previous Injury & $\begin{array}{l}\text { Evidence strongly supports prior injury as risk } \\
\text { factor for future injury in the lower extremity } \\
\text { in adolescent runners. }\end{array}$ & A \\
\hline $\begin{array}{l}\text { Height and } \\
\text { Weight }\end{array}$ & $\begin{array}{l}\text { Evidence does not support height or weight } \\
\text { as risk factors for injury in adolescent } \\
\text { cross country runners. There are no studies } \\
\text { assessing how the change in height and } \\
\text { weight impacts injury in the pre-adolescent } \\
\text { youth runner. }\end{array}$ & B \\
\hline
\end{tabular}

$\begin{array}{lll}\begin{array}{l}\text { Body mass } \\ \text { index (BMI) }\end{array} & \begin{array}{l}\text { Evidence supports low-normal BMI as a } \\ \text { risk factor for stress fracture in adolescent } \\ \text { girls. Higher BMI may be a risk factor for } \\ \text { medial tibial stress syndrome in adolescent } \\ \text { cross country runners. There are no studies } \\ \text { assessing how the change in BMI impacts } \\ \text { injury in the pre- adolescent youth runner. }\end{array} \\ \text { To date, there are no consistent data } \\ \text { addressing either age or developmental } \\ \text { stage as a risk factor for injury among youth } \\ \text { runners. }\end{array}$

\begin{tabular}{|c|c|c|}
\hline $\begin{array}{l}\text { Alignment and } \\
\text { Strength }\end{array}$ & $\begin{array}{l}\text { Limited evidence supports quadriceps } \\
\text { angle }>20 \text { degrees, muscle weakness (hip } \\
\text { abductors, knee extensor and knee flexors), } \\
\text { and leg-length inequality (boys }>1.5 \mathrm{~cm} \text { ) as } \\
\text { risk factors for injury in youth runners. }\end{array}$ & B \\
\hline $\begin{array}{l}\text { Alignment and } \\
\text { Strength }\end{array}$ & $\begin{array}{l}\text { Exercise-based programmes containing } \\
\text { elements of high intensity neuromuscular } \\
\text { training, jumping/plyometrics, and balance } \\
\text { training may help reduce injury risk in youth } \\
\text { runners, but prospective studies are needed. }\end{array}$ & C \\
\hline \multicolumn{3}{|l|}{ BONE HEALTH } \\
\hline $\begin{array}{l}\text { Bone Stress } \\
\text { Injury }\end{array}$ & $\begin{array}{l}\text { Limited evidence supports primary } \\
\text { amenorrhea, BMl }<19 \mathrm{~kg} / \mathrm{m}^{2} \text {, prior } \\
\text { participation in gymnastics or dance and prior } \\
\text { fracture as risk factors for bone stress injury } \\
\text { in female adolescent runners. }\end{array}$ & B \\
\hline
\end{tabular}

\begin{tabular}{|ll}
\hline Low BMD & $\begin{array}{l}\text { Limited evidence supports menstrual } \\
\text { dysfunction, low BMI, prior bone stress } \\
\text { injury or fracture, and longer participation } \\
\text { in endurance running as risk factors for low } \\
\text { BMD in female adolescent runner. }\end{array}$ \\
\hline Low BMD & $\begin{array}{l}\text { Limited evidence for risk factors for low BMD } \\
\text { in male runners include: low BMI, prior bone } \\
\text { stress injury, low dairy intake, running }>30 \\
\text { miles per week, and the belief that being } \\
\text { thinner leads to faster running performances. }\end{array}$ \\
\hline Menstrual & $\begin{array}{l}\text { Limited evidence supports primary } \\
\text { amenorrhea and menstrual dysfunction as } \\
\text { risk factors for bone stress injury and low } \\
\text { BMD in female adolescent runners. }\end{array}$ \\
\hline
\end{tabular}

BMD, bone mineral density; BMI, body mass index; SORT, strength of recommendation taxonomy.

BMI $<19 \mathrm{~kg} / \mathrm{m}^{2}$ had nearly three times greater risk for bone stress injury (HR 2.67, 95\% CI 1.11 to $6.41, \mathrm{p}=0.01$ ) than those with a BMI $>19 \mathrm{~kg} / \mathrm{m}^{2} .{ }^{17}$ Similar to height and weight, future studies are needed to assess how changes in BMI during growth impact injury.

STATEMENT: Evidence does NOT support height or weight as risk factors for injury in adolescent cross country runners. There are no studies assessing how the change in height and weight impacts injury in the pre-adolescent youth runner. (SORT B) STATEMENT: Evidence supports low-normal BMI as a risk factor for stress fractures in adolescent girls. Higher BMI may be a risk factor for medial tibial stress syndrome in adolescent cross country runners. There are no studies assessing how the change in BMI impacts injury in the pre-adolescent youth runner. (SORT B)

\section{Age}

Age is a non-modifiable risk factor for running injury. Several studies have attempted to determine injury rates in runners of different ages and ability levels. From 1994 to 2007, a total of 225344 children (ages 6-18 years) presented to US emergency departments with running-related injuries. The highest injury rate (45.8 per 100000 US population) was in runners aged $12-14$ years old when compared with other child age groups. ${ }^{4}$ Interestingly, a study of youth marathon runners (ages 7-17 years old) reported an incidence injury rate of 12.9 per 1000 finishers; half the rate of adult runners in the same race. ${ }^{18}$

Despite these reported rates, information relating to age and running-related injuries in the youth runner is limited and conflicting. Two prospective studies of HS cross-country runners, ages 13-18 years, showed no difference in the average age between injured and non-injured runners based on overall injury rate $(15.6 \pm 1.3$ years vs $15.6 \pm 1.1$ years, respectively $(\mathrm{p}=0.80))^{19}$ or the development of medial tibial stress syndrome $(15.3 \pm 1.0$ years vs $15.7 \pm 1.5$ years, respectively $(p>0.05)) .{ }^{20}$ In contrast, a study of 103 national elite youth runners comparing age groups suggest age and training intensity impacted injury. In this study, injured athletes, compared with non-injured athletes, completed more high-intensity training sessions (self-reported hard or very hard) at age $13-14$ years $(\mathrm{p}<0.01)$ and $15-16$ years $(\mathrm{p}<0.05)$, trained at a higher intensity at age $13-14$ years $(\mathrm{p}<0.01)$, and had a higher yearly training volume (hours) at $13-14$ years $(p<0.01) \cdot{ }^{21}$ Age alone does not appear to be a risk factor for injury in adolescent runner based on the equivocal findings of these studies. As previously noted, no studies address developmental stages as a risk factor for injury when comparing prepubescent, pubescent and postpubescent runners.

STATEMENT: To date, there are no consistent data addressing either age or developmental stage as a risk factor for injury among youth runners. (SORT B)

\section{Sex}

Sex has been examined as a risk factor for injury in HS cross country and track athletes based on self-report by runners, and/ or reporting by coaches and sports medicine professionals. Since 1978, 8 of 14 studies showed a higher incidence of HS cross country running injuries in girls than boys. ${ }^{14} 16172022-31$ Five prospective studies examining running injury per athletic exposures (AEs) during practice or competition found girls had higher injury rates than boys. A 15-year prospective study of 3,233 HS runners reported overall injury rates of 16.7/1000 AEs for girls and 10.9/1000 AEs for boys (rate ratio (RR) 1.5, 95\% CI 1.4 to $1.7 ; \mathrm{p}<0.05) .{ }^{25}$ Another prospective study of $421 \mathrm{HS}$ runners found a similar RR of $1.3(95 \%$ CI 1.0 to $1.6 ; \mathrm{p}<0.045)$ for overall injuries in girls compared with boys (19.6 vs 15.0 per $1000 \mathrm{AEs}) .{ }^{14} \mathrm{~A}$ more recent 8 -year prospective study reported an RR of 1.96 for girls sustaining a stress fracture compared with boys based on AEs (10.62 vs 5.42 per $100000 \mathrm{AEs}) .^{23}$

In HS track, most studies since 1981 (7 of 11, 63.6\%) demonstrated girls had more injuries than boys. ${ }^{17222326-3032-35}$ Of the 
Table 2 Extrinsic risk factors for injury in the youth runner

\begin{tabular}{lll}
\hline Topic & Statement & SORT rating \\
\hline Training & $\begin{array}{l}\text { Limited evidence supports low step rate as a risk factor for shin injury. } \\
\text { Training }\end{array}$ & $\begin{array}{l}\text { Limited evidence supports training less than } 8 \text { weeks during the summer as a risk factor for in-season injury in adolescent } \\
\text { runners. } \\
\text { Limited evidence supports running predominantly on hills or infrequent alternating short and long training mileage during } \\
\text { the summer as risk factors for in-season injury in adolescent runners, especially girls. }\end{array}$ \\
\hline Training & $\begin{array}{l}\text { Limited evidence supports training intensity as a risk factor for injury in adolescent runners. } \\
\text { Training }\end{array}$ & $\begin{array}{l}\text { Limited evidence does not support any specific running surface type during summer or seasonal training/competition as a } \\
\text { risk factor for injury that may be incurred during a competitive season in adolescent cross country runners. }\end{array}$ \\
\hline Training & $\begin{array}{l}\text { There are no prospective data available regarding the impact of footwear on injury risk in youth runners. } \\
\text { Footwear and Footstrike Mechanics }\end{array}$ \\
\hline Footwear and Footstrike Mechanics & $\begin{array}{l}\text { There are no reports available to assess if inherent footstrike mechanics or specific interventions to change footstrike } \\
\text { mechanics alter the risk of injury in youth runners. }\end{array}$ \\
\hline
\end{tabular}

SORT, strength of recommendation taxonomy.

four studies that controlled for AEs, girls had higher rates of running related injuries compared with boys. ${ }^{22} 233233$ In a 6-year longitudinal study of HS track and field athletes, girls had higher overall injury rates (RR 1.37 ; 95\% CI 1.27 to 1.48 ) and practice injury rates (RR $1.60 ; 95 \%$ CI 1.46 to 1.76$)$ than boys, but injury rates during competition were similar (RR 0.93 ; 95\% CI 0.80 to 1.07). ${ }^{32}$

Only one study has assessed injury rates by sex in cross country runners and track and field athletes at the middle school (MS) level, typically ages $11-13$ years. This 20 -year longitudinal study demonstrated higher rates of injury among girl cross-country runners (10.9/1000 AEs) than boys (8.0/1000 AEs) (RR 1.36, $95 \%$ CI 1.2 to $1.6 ; \mathrm{p}<0.0001) .{ }^{36}$ Similarly, girl track and field athletes had greater rates of injury (12.2/1000 AEs) than boys (8.3 per 1000 AEs) (RR $1.46,95 \%$ CI 1.3 to 1.6 ; $\mathrm{p}<0.0001) .^{36}$

Four large prospective longitudinal studies found that girl HS cross-country runners and track and field athletes had greater time loss from participation due to injury than boys in the same sports. Girl cross country runners (RR 2.6; 95\% CI 1.0 to 7.5 ) and track and field athletes (RR 2.6; 95\% CI 1.7 to 4.0 ) were more likely to have a medical disqualifying injury than boys. ${ }^{22}$ Girl cross country runners had a higher rate of bone stress injuries compared with boys (10.62 vs 5.42 for $100000 \mathrm{AEs}) .^{23}$ Two studies of HS cross-country runners found that the rate of injuries with $\geq 15$ days of time loss were 1.5-3.2 times higher for girls than boys $(\mathrm{p}<0.0001) .{ }^{14} 25$ In summary, these studies strongly suggest that girls are at a greater risk for running related injuries and greater time-lost injuries compared with boys. Future research should explore specific factors that explain this difference and strategies that may help to reduce injury.

STATEMENT: Evidence strongly supports girls are at higher risk for running related injury and greater time loss from injury than boys. (SORT A)

\section{Previous injury}

Previous injury is a common risk factor for both reinjury and new injury in sports. Based on cohort studies of competitive HS runners, there is an increased risk for lower extremity injuries for runners with a previous injury versus those without, with a RR ranging from 1.2 to $9.14 .{ }^{1416} 1724{ }^{25}$ A prospective study of 748 competitive HS runners ages 14-18 years (442 girls, 326 boys) reported a history of a prior fracture is associated with a sixfold to sevenfold increased risk for stress fracture for both boys and girls. ${ }^{17}$ A single season prospective study of 421 runners (186 girls, 235 boys), ages 14-18 years, identified an injury during preseason summer training for girls and a history of any previous running injury for boys, when adjusted for mileage on terrain, as important factors associated with increased risk of in-season injury (RR $1.64,95 \%$ CI 1.04 to $2.61, \mathrm{p}<0.05) .{ }^{14}$ In this study, most injuries $(77.6 \%)$ were minor with $<1$ week of time-loss from running. Further research is needed to assess the relationship between preventative interventions based on specific prior injuries and future injury risk in youth runners.

STATEMENT: Evidence strongly supports prior injury as risk factor for future injury in the lower extremity in adolescent runners. (SORT A)

\section{Alignment and strength}

Various studies have attempted to assess the impact of alignment, strength and balance on in-season injury in HS runners. Measures of static lower limb alignment including larger Q-angle and leglength inequality have been identified as risk factors for injury. A study of 393 HS cross country runners ages 14-18 (171 girls, 222 boys) examined the association of an increased Q-angle and actual leg-length inequality with in-season injury. A runner with a Q-angle $\geq 20^{\circ}$ of valgus alignment had an RR for injury of 1.7 (95\% CI 1.2 to $2.4, \mathrm{p}<0.05$ ) compared with runners with a lesser Q-angle. ${ }^{37}$ In the same cohort, boys with an actual leglength inequality $>1.5 \mathrm{~cm}$ had over seven times greater risk (RR $7.47,95 \%$ CI 1.5 to $36.9, \mathrm{p}=0.05$ ) for a running-related injury compared with boys with an actual leg-length inequality of $<0.5 \mathrm{~cm} .{ }^{38}$ These studies suggest that screening for Q-angle and leg-length inequality may identify runners at increased risk for injury. Other studies of cross country runners, ages 13-18 years, have shown that foot type (pronated, neutral or supinated) (right foot: $X^{2}=1.99, p=0.37$; left foot: $\left.X^{2}=1.13, p=0.57\right)^{24}$ and navicular drop $>10 \mathrm{~mm}(\mathrm{OR} 0.9,95 \% \text { CI } 0.3 \text { to } 2.8, \mathrm{p}>0.05)^{16}$ were not associated with an increased risk for in-season running injury. Additionally, a study of 230 cross country runners ages 15-18 (96 girls, 134 boys) identified increased hip internal rotation angle in girls as a risk factor for medial tibial stress syndrome over 3 years (adjusted OR 0.91 ; $95 \%$ CI 0.85 to 0.99$).{ }^{15}$

Hip and lower limb muscle weakness patterns have not been consistently shown to contribute to injury risk in youth runners. A prospective study of 68 HS cross country runners ages 13-18 years (47 girls, 20 boys) identified weak hip abductors $(p=0.046)$, knee extensors $(p=0.038)$ and knee flexors $(p=0.046)$ as significant for higher incidence of anterior knee pain, but not shin pain, during the competitive season. ${ }^{39}$ Conversely, a prospective study of 98 HS runners (45 girls, 54 boys), ages 13-18 years, found greater baseline hip abduction normalised torque percent (OR 5.35; 95\% CI 1.46 to 19.53 , 
$\mathrm{p}<0.01)$ and abduction-to-adduction normalised torque percent (OR 14.1; 95\% CI 0.90 to $221.06, \mathrm{p}=0.05$ ) were risk factors for future patellofemoral pain. ${ }^{40}$ Of note, strength was assessed in the above studies with a maximum volitional isometric effort using a handheld dynamometer.

Considering the uncertainty involving muscle weakness and imbalances as risk factors for injury in young runners, ${ }^{39} 40$ there are no interventional studies that demonstrate specific strengthening programmes modify injury risk. Exercise-based injury prevention programmes with elements of high intensity neuromuscular training, jumping, plyometrics and balance training can reduce injuries in youth athletes participating in ball sports (eg, basketball, soccer, football, volleyball, handball), but this has not been shown in runners. ${ }^{41-43}$ Despite the lack of evidence specific to youth running, neuromuscular training that incorporates running-specific functional movements progressing from double-leg to single-leg squats and hops to more demanding plyometrics and multidirection activities would be a reasonable approach to injury reduction in runners.

STATEMENT: Limited evidence supports quadriceps angle $\geq 20$ degrees, and leg-length inequality (boys $>1.5 \mathrm{~cm}$ ) as risk factors for injury in youth runners. (SORT B)

STATEMENT: Exercise-based programs containing elements of high intensity neuromuscular training, jumping/plyometrics, and balance training may help reduce injury risk in youth runners, but prospective studies are needed. (SORT C)

\section{Bone health and risk for bone stress injury}

Youth runners, especially girls, are at risk for bone stress injury as evidenced by cross country runners experiencing the first (girls) and third (boys) highest rates of bone stress injury per AE among US HS athletes, respectively. ${ }^{23}$ In girls ages 9-15 years followed prospectively for 7 years, an increasing number of hours participating in cross country running was a risk factor for bone stress injury. ${ }^{44}$ For each year delay in onset of menarche, there was a $34 \%$ increase in risk for bone stress injury. ${ }^{44}$ As previously discussed, girls with a BMI $<19 \mathrm{~kg} / \mathrm{m}^{2}$ have nearly three times greater risk for bone stress injury (HR 2.67, 95\% CI 1.11 to $6.41, \mathrm{p}=0.01)$ than those with a BMI $\geq 19 \mathrm{~kg} / \mathrm{m}^{2} .{ }^{17}$ Additional risk factors for bone stress injury include age of menarche $>15$ years of age, oligo/amenorrhea after menarche, prior fracture and prior participation in gymnastics or dance. ${ }^{1744} 45$ While gymnasts often have better than average bone density, the association of gymnastics and bone stress injury in girls is unexpected. Increased risk of bone stress injury may be due to behaviours associated with participation in aesthetic sports or selection bias in prior gymnasts and dancers who choose to run competitively. ${ }^{17}$ Total impact loading in multisport athletes was suggested as an additional explanation for runners who also participate in dance and/ or gymnastics, however, athlete participation in multiple sports at time of injury was not reported. In male adolescent runners, a history of fracture increased the risk for bone stress injury, while participation in basketball, which involves jumping and multidirectional movement, appeared protective for sustaining a stress fracture. $^{17}$

Bone mineral density (BMD) has been assessed in limited populations of youth runners. For youth participating in weightbearing sports, such as running, the term 'low bone density for age' is defined as a dual energy absorptiometry BMD Z-score $\leq-1.0$ in female athletes ${ }^{46}$ and a similar threshold has been proposed in male athletes. ${ }^{47}$ Notably, the concept and definition for low BMD has not been evaluated specifically in preadolescent runners and limited studies have evaluated these measures in adolescent runners. Within adolescent runners, BMI $\left(\leq 17.5 \mathrm{~kg} / \mathrm{m}^{2}\right)$ has been associated with increased risk of low bone density for age in both sexes, and estimated body weight below $85 \%$ of expected weight has been related to increased risk of low bone density in male runners. ${ }^{47} 48$ The belief that being thinner leads to faster running performances is associated with elevated risk for impaired bone health. ${ }^{48}$ In a population of 69 youth athletes (primarily composed of male adolescent runners), additional factors associated with impaired bone health included prior stress fracture, consuming fewer than one serving of dairy product per day and completing on average greater than 30 miles per week of training within the past year. ${ }^{47}$ Lower BMD in female adolescent runners is associated with menstrual dysfunction, prior bone stress injury, lower lean mass and more than five consecutive seasons of participation in endurance sports. ${ }^{45} 48-50$ These studies suggest female runners may be at increased risk for bone stress injury due to menstrual dysfunction and low BMI, while male runners are at increased risk of bone stress injury due to prior history of bone injury and low BMI.

STATEMENT: Limited evidence supports primary amenorrhea, BMI $<19 \mathrm{~kg} / \mathrm{m}^{2}$, prior participation in gymnastics or dance, and prior fracture as risk factors for bone stress injury in female adolescent runners. (SORT B)

STATEMENT: Limited evidence supports menstrual dysfunction, low BMI, prior bone stress injury or fracture, and longer participation in endurance running as risk factors for low BMD in female adolescent runners. (SORT B)

STATEMENT: Limited evidence supports prior fracture as a risk factor for bone stress injury in male adolescent runners and participation in basketball may reduce risk for bone stress injury. (SORT B).

STATEMENT: Limited evidence supports low BMI, prior bone stress injury, low dairy intake, running $>30$ miles per week, and belief that being thinner leads to faster running performances are risk factors for low BMD in male adolescent runners. (Sort B).

\section{Extrinsic factors}

Training

A variety of factors impacting training such as terrain, pace, intensity and training errors (eg, excessive weekly mileage, sudden change of training routines) have been thought to increase the risk of injury in youth and adult runners. While several prospective cohort studies involving HS runners have attempted to address these factors, there are no reports available examining either MS age or younger populations of runners. Three HS studies examined running terrain and training errors as risk factors during an interscholastic season. ${ }^{14551} \mathrm{~A}$ prospective study of $421 \mathrm{HS}$ cross country runners found running on concrete surfaces or flat-irregular terrains increased the risk of injury by $12 \%$ for each mile run; however, the statistical trends were not significant (HR 1.12, 95\% CI 0.99 to 1.26 and $95 \%$ CI 0.90 to 1.40 , respectively $\mathrm{p}>0.05) .{ }^{14}$ Further study of this cohort found no associations between running injury and the following training-related risk factors: running experience ${ }^{19}$ (adjusted RR 1.1, 95\% CI 0.7 to 1.9 for 0 years' experience); running pace ${ }^{14}$ (easy: HR $1.06,95 \%$ CI 0.95 to 1.18 ; moderate: HR 0.97 , 95\% CI 0.86 to 1.10 ); hard: HR 1.08 , 95\% CI 0.92 to 1.25$)$ in either practice or competition; grass, soft ground, hard ground, asphalt surfaces ( $\mathrm{HR}=1.00-1.12$, 95\% CI 0.89 to 1.26) or topography (such as flat and alternating hills or hills) $(\mathrm{HR}=1.00-1.12$, 95\% CI 0.87 to 1.40$) .{ }^{14} \mathrm{~A}$ prospective study of 68 HS cross-country runners during a season established an association between low step rate and shin injury. Runners below 
a step rate of $164 \mathrm{steps} / \mathrm{min}$ at a fixed speed of $3.3 \mathrm{~m} / \mathrm{s}$ were almost seven times more likely to incur a shin injury (OR 6.67, $95 \%$ CI 1.2 to $36.7 ; \mathrm{p}=0.03) .{ }^{51}$ At self-selected speeds, runners with step rate $<166$ steps/min were almost six times more likely to incur a shin injury (OR 5.85, 95\% CI 1.1 to $32.1 ; \mathrm{p}<0.04$ ). ${ }^{51}$

A prospective study of 421 HS cross-country runners (186 girls, 235 boys) examined the relationship between summer training practices and risk of injury during the first month of the season in adolescent runners. ${ }^{19}$ Among runners who trained during the summer, those who ran eight or fewer weeks (OR $2.7,95 \%$ CI 1.2 to $5.8, \mathrm{p}<0.05$ ) or infrequently altered short and long mileage on different days (OR 3.0, 95\% CI 1.4 to 6.4, $\mathrm{p}<0.05$ ) were more likely to be injured during the first month of the season, especially girls. Female adolescent runners who trained predominantly on hills $>33 \%$ of each run (OR 12.3, $95 \%$ CI 2.9 to $52.5, \mathrm{p}=0.001$ ) or flat irregular terrains $>33 \%$ of each run were more likely to be injured during the first month of the season (OR 12.3, 95\% CI 2.2 to 6.2, $\mathrm{p}=0.004$ ). All other combinations of training frequency (adjusted OR 1.5, 95\% CI 0.7 to 2.9 ), mileage (adjusted OR $2.5,95 \% \mathrm{CI} 0.9$ to 6.8 ), surface (adjusted $\mathrm{OR}=0.7-1.6,95 \% \mathrm{CI} 0.3$ to 4.8 ) and terrain (adjusted $\mathrm{OR}=0.7-2.2,95 \% \mathrm{CI} 0.4-5.9$ ) during summer work outs were not associated with an injury during the first month of the season $(\mathrm{p}>0.05){ }^{19}$

A few studies have attempted to assess training load (volume and intensity) and risk of injury. A study of 110 elite youth runners (64 girls, 46 boys), ages 13-17 years, assessing training load index (defined as reported intensity $\mathrm{x}$ minutes of training per week), noted athletes in the third quartile (HR 1.76, 95\% CI 1.13 to $2.76, \mathrm{p}=0.013$ ) and fourth quartile (HR 1.81, 95\% CI 1.18 to $2.80, \mathrm{p}=0.007$ ) had almost twice the risk of overuse injury compared with their peers in in the first quartile based on a 12-month prospective surveillance study. ${ }^{52} \mathrm{~A}$ study of 103 elite youth runners (66 girls, 37 boys), ages 13-17 years, found injured runners trained at a higher intensity at ages 13-14 years $(\mathrm{p}<0.01)$, higher yearly training loads at age $13-14$ years $(\mathrm{p}<0.01)$, and completed more high-intensity training sessions at both age $13-14$ years $(\mathrm{p}<0.01)$ and age $15-16$ years $(\mathrm{p}<0.05)$ compared with non-injured runners. ${ }^{21} \mathrm{~A}$ cross-sectional evaluation in 748 HS runners identified higher average weekly mileage $(17.1 \pm 11.9$ vs $14.1 \pm 11.5, \mathrm{p}<0.05)$ in injured boys, but not in girls $(14.4 \pm 10.2$ vs $12.6 \pm 11.8, \mathrm{p}>0.05) .{ }^{53}$

\begin{abstract}
STATEMENT: Limited evidence supports low step rate as a risk factor for shin injury. (SORT B)

STATEMENT: Limited evidence supports training less than 8 weeks during the summer as a risk factor for in-season injury in adolescent cross country runners. (SORT B)
\end{abstract}

STATEMENT: Limited evidence supports running predominantly on hills or infrequently alternating short and long training mileage during the summer as risk factors for an in-season injury in adolescent runners, especially for girls. (SORT B)

STATEMENT: Limited evidence supports training intensity as a risk factor for injury in adolescent runners. (SORT B)

STATEMENT: Limited evidence does NOT support any specific running surface type during summer or seasonal training/ competition as a risk factor for an injury that may incur during a competitive season in adolescent cross country runners. (SORT B)

\section{Footwear and Footstrike mechanics}

Running footwear may influence running mechanics and potentially predispose an athlete to injury. Studies assessing the impact of footwear modifications on injuries in adults have not demonstrated any consistent preventative effects despite 50 years of running shoe development. ${ }^{54-56}$ One cross-sectional study has investigated the association between habitual footwear use with lower limb injury in 76 active children from the Kalenjin tribe of Kenya. ${ }^{57}$ Habitually barefoot adolescents were significantly more physically active and had a substantially lower injury prevalence compared with habitually shod adolescents (8\% barefoot vs $61 \%$ in shod; $\mathrm{p}=0.01) .{ }^{57}$ The limited evidence in adolescents has led to speculation that barefoot or minimalist footwear might reduce injury risk, but prospective research assessing the risk of long-term injury is needed to appropriately evaluate this potential risk relationship.

Studies of footstrike mechanics in adolescent runners show conflicting information based on the population studied. Habitually barefoot runners from Kenya ( 37 males, 34 females, ages 11-17 years) had less dorsiflexion at footstrike and a lower rate of rearfoot striking (RFS) compared with their shod counterparts. ${ }^{58}{ }^{59}$ Greater dorsiflexion at footstrike and more RFS patterns were noted when comparing cushioned footwear to minimal footwear or barefoot in preadolescent or adolescent South African and German children during running. ${ }^{6061}$ In contrast, a study of 288 South African and 390 German children, age 6-18 years, noted that habitually barefoot children exhibited a higher rate of RFS than those who were habitually shod $(p<0.001) .{ }^{62}$ Interestingly, this higher rate of RFS declined as the habitually barefoot children reached adolescence. ${ }^{60}$ Thus, inherent footstrike mechanics appear to be influenced by footwear and age; however, there are no reports based on a prospective design available that indicate if inherent footstrike mechanics or interventions to change footstrike mechanics alter the risk of injuries in youth runners.

STATEMENT: There are no prospective data available regarding the impact of footwear on injury risk in youth runners. (SORT C) STATEMENT: There are no reports available to assess if inherent footstrike mechanics or specific interventions to change footstrike mechanics alter the risk of injury in youth runners. (SORT C)

\section{FACTORS THAT MAY IMPACT LONG-TERM HEALTH}

There are a variety of other factors one should consider in the youth runner that may impact long term health. The following section addresses selected topics and provides consensus statements (table 3) due to the lack of prospective studies addressing youth running.

\section{Does youth running contribute negatively to long-term cardiac health and risk of sudden cardiac death?}

Vigorous exercise, including running, results in a myriad of changes in the cardiovascular system that are generally thought to be healthy and adaptive. Though it has been debated as to whether the hearts of children are 'trainable' prior to puberty, cardiac enlargement that does not depend on age has been documented in youth athletes. ${ }^{63}$ More recently, longitudinal data have demonstrated the genesis of cardiac enlargement during endurance exercise training in youth athletes, supporting a temporal relationship between cardiac remodelling and training similar to adult endurance athletes. ${ }^{64-66}$ There are no reports available that have evaluated whether exercise-induced cardiac remodelling has any impact on the long-term health of youth runners.

Recognition of normal patterns of exercise-induced cardiac adaptation in youth runners is especially important in the context of interpreting the results of preparticipation or clinical cardiac evaluations. The primary goal of such evaluation is to exclude cardiac conditions such as cardiomyopathy, congenital disease 


\begin{tabular}{|c|c|c|}
\hline Topic & Statement & SORT rating \\
\hline Cardiovascular & $\begin{array}{l}\text { Youth athletes may experience exercise-induced cardiac adaptations similar to that seen in adults; more data are needed about the long-term } \\
\text { health implications of these findings. }\end{array}$ & B \\
\hline Cardiovascular & Rates of sudden cardiac arrest/sudden cardiac death are low in adolescent runners. & B \\
\hline Screening & $\begin{array}{l}\text { The PPE may identify prior injuries in youth runners, but research is needed to assess its effectiveness as a screening tool and ability to affect } \\
\text { future outcomes. }\end{array}$ & C \\
\hline Screening & $\begin{array}{l}\text { Screening for low EA is important for both male and female youth runners. While additional prospective studies are needed to evaluate their } \\
\text { use, screening tools such as the Triad RTPC and/or RED-S CAT are recommended to identify risk factors and address factors including low EA } \\
\text { and menstrual dysfunction that may contribute to impaired BMD and risk for injury. }\end{array}$ & C \\
\hline Screening & $\begin{array}{l}\text { Youth runners should undergo preparticipation cardiovascular evaluation using the focused history and physical exam based on the AHA-14 } \\
\text { question survey or the PPE fifth edition monograph. The use of additional testing (eg, ECG) should be based on available cardiology expertise } \\
\text { and resources or local, national, or sport federation requirements. }\end{array}$ & C \\
\hline Nutrition & $\begin{array}{l}\text { Youth runners of both sexes require adequate EA to promote optimal sports performance and support growth. As specific EA requirements } \\
\text { for individual runners vary and that specific thresholds for adequate EA to support health and performance in this population are unknown, } \\
\text { prospective studies are needed to determine appropriate and safe requirements for EA in youth runners. (SORT C) }\end{array}$ & C \\
\hline Nutrition & $\begin{array}{l}\text { In youth runners, meeting recommended intake levels of micronutrients, including calcium and vitamin D, paired with adequate EA, may } \\
\text { promote optimal bone health and reduce risk of bone stress injury. }\end{array}$ & C \\
\hline
\end{tabular}

AHA, American Heart Association; BMD, bone mineral density; RED-S CAT, Relative Energy Deficiency in Sports Clinical Assessment Tool; EA, energy availability; PPE, preparticipation physical evaluation; Triad RTPC, female athlete triad return to play criteria; SORT, strength of recommendation taxonomy.

or arrhythmia that would increase the risk of sudden cardiac arrest (SCA) and sudden cardiac death (SCD). Available reports suggest that SCD among youth runners is a very rare event. In the Minnesota State HS League, the rate of SCD was 0.24 per 100000 athlete-years with SCD occurring in four athletes, of which two were male cross country runners. ${ }^{67} \mathrm{~A}$ separate investigation in organised youth sports reported 45 sudden deaths ( 34 of 45 cardiac related) at a rate of 1.83 per 10 million athleteyears. ${ }^{68}$ The largest number of deaths occurred in boys' basketball, while only two occurred in cross country and one in track. ${ }^{68}$ Similarly, a larger multistate prospective registry of HS athletes identified 35 SCA events and 69 SCD events for a rate of SCD of 0.99 per 100000 athlete-years, with over $88 \%$ of events in males and over half in football and basketball players. ${ }^{69}$ Overall, SCA/ $S C D$ events are rare in youth runners.

STATEMENT: Youth athletes may experience exercise-induced cardiac adaptations similar to that seen in adults; more data are needed about the long-term health implications of these findings. (SORT B)

STATEMENT: Rates of SCA/SCD are low in adolescent runners. (SORT B)

\section{Are there evaluation tools to help identify athletes at risk for injury or illness?}

The preparticipation physical evaluation (PPE) may help identify risk factors for MSK injury in the youth runner. The PPE fifth edition ${ }^{70}$ suggests using a functional assessment cascade, including a double leg squat, a single leg squat and a drop box test (to evaluate for neuromuscular control and strength deficits) may decrease the risk of patellofemoral pain syndrome in runners. However, there are currently no reports available that have assessed the effectiveness of this screening cascade for preventing injury in the youth runner.

Several screening tools may be used to assess issues related to energy availability (EA). The PPE fifth edition questionnaire queries for history of eating disorder and special diet strategies, but does not include formal screening for low EA. To improve the reliability of determining EA in youth runners, one should consider adding Female Athlete Triad (Triad) and/or Relative Energy Deficiency in Sports (RED-S) screening questionnaires and incorporate the Triad Return to Play criteria (Triad RTPC) and/or the RED-S clinical assessment tool (RED-S CAT), ${ }^{71}$ which address EA in greater detail in both boys and girls. EA plays an important role in the long-term health and the shortterm performance and injury risk of youth runners. ${ }^{73}$ Low EA and associated consequences of Triad/RED-S increase risk for bone stress injury ${ }^{71}{ }^{73}$ Female youth runners with multiple triad risk factors (including BMI $<19 \mathrm{~kg} / \mathrm{m}^{2}$, age of menarche $\geq 15$ years, and prior fracture) are at risk for future bone stress injury. ${ }^{17}$ Identifying youth runners in higher risk categories can be used to modify training, begin individual sports nutrition education with a dietitian, and assess other medical concerns.

There are a variety of evaluation tools targeted at identifying risk in youth athletes of important medical conditions, such as cardiovascular disease. Though they differ, the cardiovascular section of the PPE fifth Edition, the American Heart Association 14-Point Preparticipation Screening Evaluation ${ }^{745}$ and the Youth Preparticipation Health Evaluation ${ }^{76}$ focus on medical history, family history and physical examination findings that may be suggestive of occult cardiac conditions for which further risk stratification prior to sports participation is indicated. Adding a 12-lead ECG to the standard cardiovascular history and physical exam may improve the sensitivity and specificity of the $\mathrm{PPE}^{74} 77$ to identify cardiovascular diseases associated with sudden cardiac death in youth runners, although SCA/ SCD is very rare in youth runners. If an ECG is included in PPE screening, contemporary guidelines for ECG interpretation in youth athletes should be used. ${ }^{78} 79$

STATEMENT: The PPE may identify prior injuries in youth runners, but research is needed to assess its effectiveness as a screening tool and ability to affect future outcomes. [SORT C]

STATEMENT: Screening for low EA is important for both male and female youth runners. While additional prospective studies are needed to evaluate their use, screening tools such as the Triad RTPC and/or RED-S CAT are recommended to identify risk factors and address factors including low EA and menstrual dysfunction that may contribute to impaired BMD and risk for injury. [SORT C]

STATEMENT: Youth runners should undergo preparticipation cardiovascular evaluation using the focused history and physical exam based on the AHA-14 question survey or the PPE $5^{\text {th }}$ edition monograph. The use of additional testing (eg, ECG) should be based on available cardiology expertise and resources or local, national, or sport federation requirements. [SORT C] 
Consensus statement

Table 4 Daily and post-exercise energy and macronutrient recommendations for youth runners*

\begin{tabular}{|c|c|c|c|}
\hline Timing / Topic & General & Female youth runner $^{\dagger}$ & Male youth runner $^{\ddagger}$ \\
\hline \multicolumn{4}{|l|}{ Daily } \\
\hline Energy & $45 \mathrm{kcal} / \mathrm{kg} \mathrm{FFM} /$ day & $\sim 2550 \mathrm{kcal}$ & $\sim 3090 \mathrm{kcal}$ \\
\hline \multicolumn{4}{|l|}{ Macronutrients } \\
\hline Carbohydrate & 6 to $10 \mathrm{~g} / \mathrm{kg} / \mathrm{day}$ & $336-560 \mathrm{~g}$ & $366-610 \mathrm{~g}$ \\
\hline Sample sources & $\begin{array}{l}\text { Fruit, starchy vegetables, whole grain bread, pasta, } \\
\text { brown rice, oatmeal, beans, legumes }\end{array}$ & & \\
\hline Protein & 1.2 to $2.0 \mathrm{~g} / \mathrm{kg} /$ day & $67-112 \mathrm{~g}$ & $73-122 \mathrm{~g}$ \\
\hline Sample sources & Chicken, tuna, lean beef, egg, milk, yoghurt & & \\
\hline Fat & 1 to $2.0 \mathrm{~g} / \mathrm{kg} / \mathrm{day}$ & $56-112 \mathrm{~g}$ & $61-122 \mathrm{~g}$ \\
\hline Sample sources & $\begin{array}{l}\text { Nuts, seeds, nut \& seed butters (eg, almond, sunflower, } \\
\text { peanut, cashew), oil-based dressing, olives, avocado }\end{array}$ & & \\
\hline \multicolumn{4}{|l|}{ Post-Exercise } \\
\hline Carbohydrate & 1.0 to $1.2 \mathrm{~g} / \mathrm{kg} / \mathrm{hour}$ & $56-67 g$ & $61-73 g$ \\
\hline Protein & $\sim 0.3 \mathrm{~g} / \mathrm{kg} 0-2$ hours post & $17 \mathrm{~g}$ & $18 \mathrm{~g}$ \\
\hline \multirow[t]{2}{*}{ Examples $^{\S}$} & & $\begin{array}{c}\# 1: \text { Smoothie } \\
\text { Two small bananas }(46 \mathrm{~g} \text { CHO, } 2 \mathrm{~g} P R O), \\
1 / 3 \text { cup Greek yoghurt }(3 \mathrm{~g} C H O, 8 g \text { PRO), } \\
1 \text { cup vanilla soymilk }(11 \mathrm{~g} \text { CHO, } 7 g \text { PRO) } \\
\text { Totals: } 60 \mathrm{~g} \text { CHO, } 17 g \text { PRO }\end{array}$ & $\begin{array}{c}\text { \#1: Bagel sandwich } \\
\text { Whole wheat bagel }(51 \mathrm{~g} \text { CHO } 11 \mathrm{~g} \text { PRO) } \\
\text { 11/2 oz. turkey }(1 \mathrm{~g} \text { CHO } 7 \mathrm{~g} \text { PRO) } \\
\text { Small apple }(21 \mathrm{~g} \text { CHO, Og PRO) } \\
\text { Totals: } 73 \mathrm{~g} \text { CHO, } 18 \mathrm{~g} \text { PRO }\end{array}$ \\
\hline & & $\begin{array}{c}\text { \#2: Oatmeal } w / \text { raisins } \\
\text { One cup oatmeal }(32 \mathrm{~g} C H O, 6 g \text { PRO) Two } \\
\text { tbsps. raisins }(16 \mathrm{~g} C H O, 0 g \text { PRO) } 1 \\
\text { cup 1\% milk }(17 \mathrm{~g} \text { CHO, } 11 \mathrm{~g} \text { PRO } \\
\text { Totals: } 65 \mathrm{~g} \text { CHO } 17 \mathrm{~g} \text { PRO }\end{array}$ & $\begin{array}{c}\text { \#2: Black bean wrap } \\
\text { Whole grain tortilla ( } 32 \mathrm{~g} \text { CHO, } 7 \mathrm{~g} \text { PRO) } \\
3 / 4 \text { cup black beans (30g CHO, } 11 \mathrm{~g} \text { PRO) } \\
\text { Totals: } 62 \mathrm{~g} \text { CHO, } 18 \mathrm{~g} \text { PRO }\end{array}$ \\
\hline
\end{tabular}

Nutrient recommendations based on values reported by Thomas et al. (2016) J Acad Nutr Diet, 116(3) 501-528, ${ }_{1}^{80}$ Coleman and Rosenbloom (2012). Sports Nutrition: A Practice Manual for Professionals, Fifth Edition, Academy of Nutrition and Dietetics, Chicago, IL, ISBN: 978-0-88091-452-1. ${ }^{108}$

*Individualised needs vary based on athletes' volume and intensity of exercise, anthropometric values, growth parameters, among other factors.

†Female youth runner based on mean anthropometric values reported in Barrack et al (2010) J Bone Miner Res 25(8):1850-7 (56 kg, 22.5\% body fat) and a mean exercise energy expenditure of $600 \mathrm{kcal} / \mathrm{day}^{109}$

¥Male youth runner based on mean anthropometric values reported in Barrack et al (2017) Br J Sports Med 51(3):200-205 (61 kg, 14.2\% body fat) and a mean exercise energy expenditure of $750 \mathrm{kcal} / \mathrm{day}{ }^{47}$

§Carbohydrate (CHO) and protein (PRO) values reported by USDA Food Data Central https://fdc.nal.usda.gov/index.html.

\section{Are there any nutritional guidelines for the youth runner?}

Nutritional intake for a youth runner should aim to support growth and development, bone health, optimal performance, recovery from activity and enhance injury prevention. Sports nutrition recommendations for youth runners emphasise maintaining adequate carbohydrate, protein, and fat intake to maintain adequate EA for a growing and developing body. Meeting the minimum recommended dietary allowance for essential vitamins and minerals is important for runners' health, including particular emphasis on iron, calcium, vitamin $\mathrm{D}$, antioxidants and $\mathrm{B}$ vitamins. Current nutrition guidelines are based on research in young adult athletes, ${ }^{80}$ thus dietitians working with youth runners should consider each athlete's stage of development and activity level when providing recommendations.

Studies investigating nutritional intake suggest that youth runners often do not meet their energy needs placing them at risk for low EA. Female HS runners report daily intakes ranging from 2000 to $2300 \mathrm{kcals}$ compared with estimated daily requirements of approximately $2500-2800 \mathrm{kcal}^{81-85}$ Male youth runners' calorie needs range from 3100 to $3600 \mathrm{kcal} / \mathrm{day} .{ }^{85} 86$ Preliminary studies also indicate that runners may underconsume key vitamins and minerals. ${ }^{81} 8384$

To promote adequate EA and intake of essential nutrients, youth runners should consume a variety of nutrient-rich whole foods during their regular daily meals and snacks (table 4). Youth runners without other medical conditions or gut malabsorption syndromes are likely to meet most primary nutrient needs through normal dietary intake. There is a potential role for vitamin D supplementation based on sun exposure, latitude, and time of year, and iron supplementation in runners who do not consume red meat, experience fatigue with associated low iron status, or have excessive blood loss, such as from heavy menstruation. ${ }^{80}$

STATEMENT: Youth runners of both sexes require adequate EA to promote optimal sports performance and support growth. As specific EA requirements for individual runners vary and that specific thresholds for adequate EA to support health and performance in this population are unknown, prospective studies are needed to determine appropriate and safe requirements for EA in youth runners. (SORT C)

STATEMENT: In youth runners, meeting recommended intake levels of micronutrients, including calcium and vitamin D, paired with adequate EA, may promote optimal bone health and reduce risk of bone stress injury. (SORT C)

\section{APPROPRIATENESS OF RUNNING AS A SPORT FOR PREADOLESCENT CHILDREN}

Data to support age or physical development criteria for training and competing in running events are not available and current guidelines are opinion based (table 5). This section will review the rationale for including children in running events and emerging data supporting safe participation.

\section{What is the role of free play in running?}

Free play promotes physical activity, movement and creativity, and cultivates friendships and socialisation. ${ }^{87}$ For preadolescent 


\begin{tabular}{|c|c|c|}
\hline Topic & Statement & SORT rating \\
\hline Specialisation & $\begin{array}{l}\text { There is limited evidence to support sport specialisation as a risk factor for overuse lower extremity injury in high school cross country and distance } \\
\text { track athletes }\end{array}$ & B \\
\hline Specialisation & $\begin{array}{l}\text { No evidence is available to define an appropriate age to start specialisation in running or to suggest that specialisation in running improves athletic } \\
\text { performance }\end{array}$ & B \\
\hline Free Play & Free play outside of the sport of running should be encouraged for the overall growth and development of youth runners & C \\
\hline $\begin{array}{l}\text { Age-Appropriate } \\
\text { Distances }\end{array}$ & $\begin{array}{l}\text { Early evidence suggests that youth runners physically and mentally prepared through a supervised training programme can participate in long distance } \\
\text { events, but may be at low risk of running-related injury }\end{array}$ & C \\
\hline $\begin{array}{l}\text { Age-Appropriate } \\
\text { Distances }\end{array}$ & $\begin{array}{l}\text { There are no studies to support specific distances or training recommendations for youth runners to prevent injury or guide normal growth and } \\
\text { development }\end{array}$ & C \\
\hline
\end{tabular}

children, play improves energy balance and evolution suggests that the brain will naturally reinforce behaviours like regular vigorous activity that improve brain and body health. ${ }^{87} 88$ Vigorous-free play is better for developing motor skills in children and naturally develops endurance with the stop-start, often high intensity, activities that children pursue when given the opportunity. ${ }^{89}$

As part of free play, preadolescent children participate in many running-based games with added health benefits. A systematic review of fundamental movement skill competencies in preadolescent children and adolescents showed a positive association between locomotor (eg, running and hopping), manipulative or object control (eg, catching and throwing), stability (eg, balancing and twisting) skills and cardiorespiratory fitness and an inverse relationship with weight status. ${ }^{90}$ In a school-based physical activity programme (cluster randomised controlled trial of fifth grade students), adding two additional physical activity sessions a week for 9 months improved cardiorespiratory fitness and reduced adiposity. ${ }^{91}$ These findings support guidelines that suggest each child should accumulate $60 \mathrm{~min}$ or more of physical activity daily. ${ }^{92} 93$

STATEMENT: Free play outside of the sport of running should be encouraged for the overall growth and development of preadolescent runners. (SORT C)

\section{What are specific recommendations for age-appropriate distances to compete in youth running?}

Evidence-based guidelines for age to start participating in the sport of running on the track, on road, or off road, when to start running in competition, and distances for training and competition are lacking. Proposed recommendations for total distance and training volume for preadolescent runners are based on opinions of coaches and health professionals. ${ }^{94-96}$ A survey of 132 cross-country coaches suggested race organisers offer races of $1.5 \mathrm{~km}$ ( 1 mile) or less for early-elementary aged children, $1.5-3 \mathrm{~km}$ (1-2 miles) for upper-elementary aged participants, and restrict participation in the marathon distance to runners 18 years and older. ${ }^{94}$ Most coaches agreed the $5 \mathrm{~km}$ distance was appropriate for those 12 years and older. ${ }^{94}$ Other opinion recommendations suggest that children ages $5-6$ years should be limited to $800 \mathrm{~m}$ 'races' and ages 7-11 years should be limited to $1600 \mathrm{~m}$ races, despite the lack of any supporting evidence. ${ }^{95}$ While these recommendations may be reasonable, there are no outcomes data to support specific distances or training recommendations for youth runners. Future research should attempt to address the issue of youth running distances and risk of injury to develop age appropriate evidence-based guidelines for distance and training recommendations.

There are child-specific running programmes associated with national running clubs, including the Boston Athletic Association,
New York Road Runners, Twin Cities in Motion, and Students Run Los Angeles (SRLA) that have attempted to address the risk of injury in youth runners. A retrospective study of 310 runners, ages 7-17 years, who participated in the Twin Cities Marathon (1982-2007) during various temperatures (wet bulb globe temperature range from $-4^{\circ} \mathrm{C}$ to $22^{\circ} \mathrm{C}$ ), reported that only four of the youth runners required finish-area medical assistance for minor medical issues (representing half the rate of medical encounters for adult finishers). ${ }^{18}$ Of the 42328 youth runners who finished the Twin Cities in Motion road races (2011-2018), only one 15-year-old boy experienced exertional heat stroke on a hot day when several adults also experienced exertional heat stroke (Roberts WO Unpublished data 2019).

SRLA (established in 1989) is a school-based 7-month marathon training programme that prepares 'socioeconomically at risk' children ages 12-18 years to run the LA Marathon. Through 2018, more than 66000 MS and HS students have completed the marathon with no reports of serious injury or death. ${ }^{97}$ Prospective data on 2308 students (roughly 50\% girls) over two separate seasons (2016-2017 and 2017-2018) indicated that $20 \%$ of runners reported pain at some point during the training programme, mostly involving the knee, foot and ankle regions. However, $99 \%$ of the participants who started on race day completed the marathon without serious injury. ${ }^{98}$ These findings suggest that with a supervised training programme, youth participating in distance running events such as marathons may be at low risk for significant injury or developmental delay during training and competition. Children participating in these running events should be prepared both physically (injury-free) and mentally (internally motivated and not pushed by parents or coaches), potentially lowering the risk of injury and burnout.

STATEMENT: There are no studies to support specific distances or training recommendations for youth runners to prevent injury or guide normal growth and development. (SORT C)

STATEMENT: Early evidence suggests that youth runners physically and mentally prepared through a supervised training program can participate in long distance events but may be at low risk of running-related injury. (SORT C)

\section{Should children specialise in running and what is an appropriate age?}

Overuse injury and burn-out related to early sport specialisation are current areas of interest in sports medicine. ${ }^{89} 99100$ Several studies of youth athletes, not specific to runners, identify sport specialisation as an independent risk factor for injury. ${ }^{101-105}$ Youth athletes who played their primary sport more than 8 months per year had more overuse injuries in upper (OR 1.68; 95\% CI 1.06 to $2.80, \mathrm{p}=0.04)$ and lower extremities (OR 1.66; 95\% CI 1.22 to $2.30, \mathrm{p}=0.001$ ). ${ }^{105}$ Youth athletes who participated in their primary sport more 
hours per week than their age in years had more injuries of any type (OR $1.34 ; 95 \%$ CI 1.12 to $1.61, \mathrm{p}=0.001)$ and were more likely to have a history of overuse injuries if training volume exceeded recommendations for age. ${ }^{105}$ Based on these findings, many organisations advocate sport sampling and diversification for youth athletes. ${ }^{99} 100$

There are limited data to answer questions about safety and appropriateness of specialisation in running at young ages. A case-control survey of 989 girls and 1022 boys age $12-18$ years $(5.6 \%$ of the cohort participating in track and cross country) found high specialisation athletes compared with low specialisation athletes had more previous injuries of any kind (OR $1.59 ; 95 \% \mathrm{CI} 1.26$ to $2.02, \mathrm{p}<0.001)$ and more overuse injuries (OR 1.45; 95\% CI 1.07 to 1.99 , $\mathrm{p}=0.011) .{ }^{105}$ A 1 -year observational study of 126 female HS cross country and distance track $(\geq 1600 \mathrm{~m})$ athletes found an increased risk of injury in high specialisation runners (RR $1.75,95 \%$ CI 1.1 to $2.7, \mathrm{p}=0.02$ ) compared with low specialisation runners. There was a disproportionate increase in lower leg injuries, severe injuries and recurrent injuries among highly specialised youth runners. ${ }^{106}$ In contrast, while a prospective study of $62 \mathrm{HS}$ track and cross country runners observed an elevated risk of lower extremities injury in high specialisation compared with low specialisation athletes, the risk estimate was not statistically significant. ${ }^{103}$ Runners who participated only in SRLA over the course of the 2018-2019 season ( $\mathrm{N}=1469,49 \%$ male, $51 \%$ female) had similar injury rates (1.19 per 1000 person-miles) as those that participated in field and court sports (1.54 per 1000 person-miles) over the course of the 2018-2019 marathon training season $\left(\mathrm{p}=0.17\right.$, bivariate analysis). ${ }^{107}$

STATEMENT: There is limited evidence to support sport specialization as a risk factor for lower extremity overuse injury in HS cross country and distance track athletes. (SORT B)

STATEMENT: No evidence is available to define an appropriate age to start specialization in running or to suggest that specialization in running improves athletic performance. (SORT C)

\section{SUMMARY AND RECOMMENDATIONS}

Reducing the risk of running-related injuries in the youth runner must take into account the complex interaction of various factors, including growth-related changes unique to this population. Though research is limited, studies have identified several risk factors for injury in the youth runner (table 6). Aligning individual growth and development with the demands of running while accounting for individual energy needs may reduce injury, overtraining, and burnout. Furthermore, readiness for running should be based on a combination of physical, biomechanical, psychological, social and cognitive factors that are driven by the athlete. It is our opinion that running initiated by youth and supervised through a comprehensive evaluation and individualised training programme that allows adequate rest and energy replacement should allow for a successful running career and promote lifelong health.

In addition to the previous statements, the following summary recommendations ${ }^{7}$ are based on expert opinion:

- Athletes should be screened for previous injuries, low BMI, low EA, menstrual dysfunction (girls), biomechanical concerns, and training errors. (SORT B)

- Youth runners should participate in high-impact and multidirectional activities with a focus on improved neuromuscular control of the lumbopelvic region and lower extremities at least through puberty to reduce injury and promote bone health. (SORT C)

- Readiness for running, especially longer distances, should be determined by growth and development rather than chronological age. (SORT C)

- Youth runners should incorporate at least one rest day per week, 1-2 weeks every 3 months, and limit participation to less than 9 months per year. (SORT C)

- To reduce the risk of burnout, single sport specialisation in running should be discouraged until boys and girls pass through puberty. (SORT C)

- Self-motivated preadolescents and adolescents should be allowed to participate in long distance running events if they follow an acceptable supervised training programme, maintain normal growth in height and weight, and remain healthy with good nutritional intake that promotes adequate EA and essential nutrients. (SORT C)

- Risk factors that require further medical evaluation are: (SORT C)

- BMI $\leq 17.5 \mathrm{~kg} / \mathrm{m}^{2}$ OR measured body weight below $85 \%$ of normal for age.

- BMD Z-score $\leq-1.0$.

- Untreated disordered eating/eating disorder or related complications (eg, arrhythmia, renal failure).

- One high-risk bone stress injury (eg, femoral neck, proximal tibia, navicular) OR youth runner with two or more bone stress injuries.

- Female runners without menarche by age 16 years old $\mathrm{OR}<6$ menstrual cycles in the past 12 months.

\section{FUTURE DIRECTIONS}

The current state of science surrounding youth runners suggests opportunities for additional research to minimise risk and improve clinical practice. These include:

1. The stage of development (prepubertal, pubescent and postpubescent) in the youth runner must be incorporated into future research endeavours.

2. More research identifying risk factors for injury during practice and competitions of varied length (eg, sprinting vs

Table 6 Summary of risk factors for injury in adolescent runners

\begin{tabular}{|c|c|c|c|}
\hline \multicolumn{4}{|l|}{ Increases risk of injury } \\
\hline Strong evidence & Limited evidence & Not supported & Conflicting evidence/unclear \\
\hline Prior Injury & Anatomical & $\underline{\text { Height }}$ & Age/development \\
\hline Sex & Quadriceps angle $\geq 20^{\circ}$ & Weight & Muscle weakness \\
\hline$\overline{\text { Girls }>\text { boys }}$ & Leg-length inequality $(>1.5 \mathrm{~cm})$ in boys & Running Surface Type & $\overline{\text { Hip abductors }}$ \\
\hline Menstrual dysfunction & Training/biomechanics & & Knee extensor \\
\hline$\overline{\mathrm{BMI}}$ & Summer training ( $<8$ weeks, $>33 \%$ on hills, $<25 \%$ alternating short & & Knee flexors \\
\hline \multirow[t]{4}{*}{$<19 \mathrm{~kg} / \mathrm{m}^{2}$ for BSI in girls } & and long mileage on different days) & & Footwear \\
\hline & & & Footstrike mechanics \\
\hline & Low running step rate (<166 steps/min) & & \\
\hline & Sports specialisation & & \\
\hline
\end{tabular}

BMI, body mass index; $\mathrm{BSI}$, bone stress injury. 
ultramarathons) when comparing age and stage of development and subsequent recommendations will assist in reducing youth running injury.

3. Additional research is needed to identify specific factors that explain the difference in running related injuries in girls compared with boys.

4. Larger prospective cohort studies that allow appropriate multivariate modelling to assess the interactions of intrinsic factors (eg, maturation, lower extremity alignment, gluteus medius strength) and extrinsic factors (eg, training error, too high or too low mileage, race distance) and their relationship to risk of injury to specific body locations or injury types are necessary.

5. Future research should assess cognitive development and mental health in the youth runner.

6. Prospective studies of the long-term effects of footwear, foot strength and running biomechanics on running injuries in the youth runner are needed.

7. More robust data are required to assess the relationship between specific interventions based on specific prior injuries or anatomical findings and their effect on future injury in youth runners.

8. Exercise-based programmes containing elements of high intensity neuromuscular, jumping/plyometric and balance training that may reduce injury risk in youth runners should be assessed.

9. Prospective outcomes-based studies are needed to better understand the utility of the PPE and the potential addition of an ECG in assessing SCA/SCD risk, the use of Triad/RED-S screening questionnaires, and the Triad RTPC and RED-S CAT in the youth runner.

10. Prospective studies to evaluate outcome of early sport specialisation on youth runner health (including injury and discontinuation of sport) and evaluating interventions to modify this risk are needed.

11. Future investigations should evaluate the dietary intake patterns of youth runners and areas of nutritional risk to identify strategies for promoting recommended intake levels of energy, macronutrients, and key micronutrients to optimise health, performance, recovery effort and reduce injury.

\section{CONCLUSION}

Despite the popularity of youth running, relatively little is known about its impact on injury and illness in this unique population. It is clear that limited research studies have identified several risk factors for injury, but future prospective studies are needed. Our Youth Running Consensus Group has critically evaluated the current state of science relating to the youth runner, while developing consensus statements to guide clinicians and researchers in the assessment and prevention of injury and illness. This consensus document reflects our current state of knowledge and will require periodic updates incorporating the development of new research, as available. The authors acknowledge that the science relating to youth running is incomplete and therefore individual management decisions should be based on clinical judgement, using an evidence-based approach.

\section{Author affiliations}

${ }^{1}$ Rehabilitation, Orthopedics and Sports Medicine, Univesrity of Washington, Seattle, Washington, USA

${ }^{2}$ Family Medicine and Community Health, University of Minnesota, St Paul, Minnesota, USA

${ }^{3}$ Physical Medicine and Rehabilitation, Spaulding Rehabilitation Hospital, Boston, Massachusetts, USA

${ }^{4}$ Sports Medicine, Boston Children's Hospital, Boston, Massachusetts, USA ${ }^{5}$ Health and Science, IAAF Health \& Science Department, International Association of Athletics Federations (IAAF), Monaco
${ }^{6}$ Cardiovascular Performance Program, Massachusetts General Hospital, Boston, Massachusetts, USA

${ }^{7}$ Family and Consumer Sciences, California State University, Long Beach, Long Beach, California, USA

${ }^{8}$ Physical Medicine and Rehabilitation, Baylor College of Medicine, Houston, Texas, USA

${ }^{9}$ Physical Medicine and Rehabilitation, National Running Center, Cambridge,

Massachusetts, USA

${ }^{10}$ Orthopaedic Surgery, Stanford University, Stanford, California, USA

${ }^{11}$ Sports Medicine, University of California Los Angeles, Los Angeles, California, USA

${ }^{12}$ Orthopedics and Rehabilitation, University of Wisconsin-Madison, Madison, Wisconsin, USA

${ }^{13}$ MSH Medical School Hamburg, Hamburg, Germany

${ }^{14}$ Orthopaedic Surgery, Stanford Hospital and Clinics, Stanford, California, USA

${ }^{15}$ Family and Community Medicine, University of California, San Francisco, San

Francisco, California, USA

${ }^{16}$ Sports Physical Therapy, Sanford Health, Sioux Falls, South Dakota, USA

${ }^{17} \mathrm{~S}$ chool of Exercise and Nutritional Sciences, Doctor of Physical Therapy Program, San Diego State University, San Diego, California, USA

${ }^{18}$ Primary Care Sports Medicine, Hospital for Special Surgery, New York, New York, USA

Correction notice This article has been corrected since it published Online First. The author, Irene Davis, has been added and tables 1, 4 and 5 updated.

Twitter Brian J Krabak BrianKrabak@BrianKrabakMD, Adam S Tenforde @AdamTenfordeMD, Kathryn E Ackerman @drkateackerman, Paolo Emilio Adami @paolo_emilio, Joshua T Goldman @DrJoshGoldman, Emily Kraus @emilykrausmd and Melissa Moyer @moyermel

Contributors All authors meet criteria for authorship for the manuscript in the following ways: substantial contribution to the conception or design of the manuscript, or the acquisition, analysis and interpretation of the data; drafting and revising the manuscript; final approval of the version publish and agreement to be accountable for all aspects of the work relating to the accuracy and integrity. No one meeting the criteria for authorship has been excluded from authorship.

Funding The authors wish to thank the following individuals and organisation for their valuable assistant in the development of this document: Andrea Ball MLS, VMA, MSIM, University of Washington for her assistance with the literature search methodology and National Youth Sports Health and Safety Institute for their conference support.

Disclaimer This consensus paper provides an overview of risk factors for injury and readiness for running in the youth athlete. It is not intended as a clinical practice guideline or legal standard of care and should not be interpreted as such. The consensus paper serves as a guide for healthcare professionals. Individual evaluation and treatment will depend on the circumstances specific to each individual case.

Competing interests None declared.

Patient consent for publication Not required.

Provenance and peer review Not commissioned; externally peer reviewed.

Supplemental material This content has been supplied by the author(s). It has not been vetted by BMJ Publishing Group Limited (BMJ) and may not have been peer-reviewed. Any opinions or recommendations discussed are solely those of the author(s) and are not endorsed by BMJ. BMJ disclaims all liability and responsibility arising from any reliance placed on the content. Where the content includes any translated material, BMJ does not warrant the accuracy and reliability of the translations (including but not limited to local regulations, clinical guidelines, terminology, drug names and drug dosages), and is not responsible for any error and/or omissions arising from translation and adaptation or otherwise.

\section{ORCID iDs}

Brian J Krabak http://orcid.org/0000-0002-7601-8464

William 0 Roberts http://orcid.org/0000-0003-4517-4330

Kathryn E Ackerman http://orcid.org/0000-0003-2626-7785

Paolo Emilio Adami http://orcid.org/0000-0001-5975-5342

Joshua T Goldman http://orcid.org/0000-0001-7329-6285

Karsten Hollander http://orcid.org/0000-0002-5682-9665

Emily Kraus http://orcid.org/0000-0001-5544-2939

\section{REFERENCES}

1 Hulteen RM, Smith JJ, Morgan PJ, et al. Global participation in sport and leisure-time physical activities: a systematic review and meta-analysis. Prev Med 2017;95:14-25.

2 Fakhouri THI, Hughes JP, Burt VL, et al. Physical activity in U.S. youth aged 12-15 years, 2012. NCHS Data Brief 2014;141:1-8

3 National Federation of HSs survey of participation. National Federation of state high school associations, 2019. Available: https://www.nfhs.org/media/1020412/201819_participation_survey.pdf 
4 Mehl AJ, Nelson NG, McKenzie LB. Running-related injuries in school-age children and adolescents treated in emergency departments from 1994 through 2007. Clin Pediatr 2011;50:126-32.

5 Nelson NG, Alhaij M, Yard E, et al. Physical education class injuries treated in emergency departments in the US in 1997-2007. Pediatrics 2009;124:918-25.

6 Krabak BJ, Tenforde AS, Davis IS, et al. Youth distance running: strategies for training and injury reduction. Curr Sports Med Rep 2019;18:53-9.

7 Krabak BJ, Snitily B, Milani CJE. Running injuries during adolescence and childhood. Phys Med Rehabil Clin N Am 2016;27:179-202.

8 United States track and field, 2020. Available: https://www.usatf.org/resources/ statistics/records/national-records

9 Moher D, Liberati A, Tetzlaff J, et al. Preferred reporting items for systematic reviews and meta-analyses: the PRISMA statement. J Clin Epidemiol 2009;62:1006-12.

10 Micheli LJ. Overuse injuries in children's sports: the growth factor. Orthop Clin North Am 1983:14:337-60.

11 Lloyd RS, Oliver JL, Faigenbaum AD, et al. Chronological age vs. biological maturation: implications for exercise programming in youth. J Strength Cond Res 2014;28:1454-64

12 Faulkner RA, Davison KS, Bailey DA, et al. Size-corrected BMD decreases during peak linear growth: implications for fracture incidence during adolescence. J Bone Miner Res 2006;21:1864-70.

13 Baxter-Jones ADG, Faulkner RA, Forwood MR, et al. Bone mineral accrual from 8 to 30 years of age: an estimation of peak bone mass. J Bone Miner Res 2011:26:1729-39.

14 Rauh MJ, Koepsell TD, Rivara FP, et al. Epidemiology of musculoskeletal injuries among high school cross-country runners. Am J Epidemiol 2006;163:151-9.

15 Yagi S, Muneta T, Sekiya I. Incidence and risk factors for medial tibial stress syndrome and tibial stress fracture in high school runners. Knee Surg Sports Traumatol Arthrosc 2013;21:556-63.

16 Plisky MS, Rauh MJ, Heiderscheit B, et al. Medial tibial stress syndrome in high school cross-country runners: incidence and risk factors. J Orthop Sports Phys Ther 2007:37:40-7.

17 Tenforde AS, Sayres LC, McCurdy ML, et al. Identifying sex-specific risk factors for stress fractures in adolescent runners. Med Sci Sports Exerc 2013;45:1843-51.

18 Roberts WO, Nicholson WG. Youth marathon runners and race day medical risk over 26 years. Clin J Sport Med 2010;20:318-21.

19 Rauh MJ. Summer training factors and risk of musculoskeletal injury among high school cross-country runners. J Orthop Sports Phys Ther 2014;44:793-804.

20 Bennett JE, Reinking MF, Pluemer B, et al. Factors contributing to the development of medial tibial stress syndrome in high school runners. J Orthop Sports Phys Ther 2001:31:504-10.

21 Huxley DJ, O'Connor D, Healey PA. An examination of the training profiles and injuries in elite youth track and field athletes. Eur J Sport Sci 2014;14:185-92.

22 Tirabassi J, Brou L, Khodaee M, et al. Epidemiology of high school sports-related injuries resulting in medical Disqualification: 2005-2006 through 2013-2014 academic years. Am J Sports Med 2016:44:2925-32.

23 Changstrom BG, Brou L, Khodaee M, et al. Epidemiology of stress fracture injuries among US high school athletes, 2005-2006 through 2012-2013. Am J Sports Med 2015;43:26-33.

24 Reinking MF, Austin TM, Hayes AM. Risk factors for self-reported exercise-related leg pain in high school cross-country athletes. J Athl Train 2010;45:51-7.

25 Rauh MJ, Margherita AJ, Rice SG, et al. High school cross country running injuries: a longitudinal study. Clin J Sport Med 2000;10:110-6.

26 Beachy G, Akau CK, Martinson M, et al. High school sports injuries. A longitudinal study at Punahou school: 1988 to 1996. Am J Sports Med 1997;25:675-81.

27 McLain LG, Reynolds S. Sports injuries in a high school. Pediatrics 1989;84:446-50

28 Lowe EB, Perkins ER, Herndon JH. Rhode island high school athletic injuries 198586. $R$ I Med J 1987;70:265-70

29 Chandy TA, Grana WA. Secondary school athletic injury in boys and girls: a threeyear comparison. J Pediatr Orthop 1985;5:629.

30 Shively RA, Grana WA, Ellis D. High school sports injuries. Phys Sportsmed 1981:9:46-50.

31 Garrick JG, Requa RK. Injuries in high school sports. Pediatrics 1978;61:465-9.

32 Pierpoint LA, Williams CM, Fields SK, et al. Epidemiology of injuries in United States high school track and field: 2008-2009 through 2013-2014. Am J Sports Med 2016:44:1463-8.

33 Knowles SB, Marshall SW, Bowling JM, et al. A prospective study of injury incidence among North Carolina high school athletes. Am J Epidemiol 2006:164:1209-21.

34 Watson MD, D PP, DiMartino PP. Incidence of injuries in high school track and field athletes and its relation to performance ability. Am J Sports Med 1987;15:251-4.

35 Requa RK, Garrick JG. Injuries in Interscholastic track and field. Phys Sportsmed 1981:9:42-9.

36 Beachy G, Rauh M. Middle school injuries: a 20-year (1988-2008) Multisport evaluation. J Ath/ Train 2014;49:493-506.

37 Rauh MJ, Koepsell TD, Rivara FP, et al. Quadriceps angle and risk of injury among high school cross-country runners. J Orthop Sports Phys Ther 2007;37:725-33.

38 Rauh MJ. Leg-Length inequality and RUNNING-RELATED injury among high school runners. Int J Sports Phys Ther 2018;13:643-51.
39 Luedke LE, Heiderscheit BC, Williams DSB, et al. Association of isometric strength of hip and knee muscles with injury risk in high school cross country runners. Int J Sports Phys Ther 2015;10:868-76

40 Finnoff JT, Hall MM, Kyle K, et al. Hip strength and knee pain in high school runners: a prospective study. $P M \& R$ 2011;3:792-801.

41 Rössler R, Donath L, Verhagen $\mathrm{E}$, et al. Exercise-based injury prevention in child and adolescent sport: a systematic review and meta-analysis. Sports Med 2014:44:1733-48.

42 Emery CAet al. Effectiveness of a home-based balance-training program in reducing sports-related injuries among healthy adolescents: a cluster randomized controlled trial. Can Med Assoc J 2005:172:749-54.

43 Richmond SA, Kang J, Doyle-Baker PK, et al. A school-based injury prevention program to reduce sport injury risk and improve healthy outcomes in youth: a pilot cluster-randomized controlled trial. Clin J Sport Med 2016;26:291-8.

44 Field AE, Gordon CM, Pierce LM, et al. Prospective study of physical activity and risk of developing a stress fracture among preadolescent and adolescent girls. Arch Pediatr Adolesc Med 2011;165:723-8.

45 Rauh MJ, Barrack M, Nichols JF. Associations between the female athlete triad and injury among high school runners. Int J Sports Phys Ther 2014:9:948-58.

46 Nattiv A, Loucks AB, Manore MM, et al. American College of sports medicine position stand. the female athlete triad. Med Sci Sports Exerc 2007;39:1867-82.

47 Barrack MT, Fredericson M, Tenforde AS, et al. Evidence of a cumulative effect for risk factors predicting low bone mass among male adolescent athletes. Br J Sports Med 2017:51:200-5

48 Tenforde AS, Fredericson M, Sayres LC, et al. Identifying sex-specific risk factors for low bone mineral density in adolescent runners. Am J Sports Med 2015;43:1494-504.

49 Barrack MT, Gibbs JC, De Souza MJ, et al. Higher incidence of bone stress injuries with increasing female athlete triad-related risk factors: a prospective multisite study of exercising girls and women. Am J Sports Med 2014;42:949-58.

50 Ackerman KE, Cano Sokoloff N, DE Nardo Maffazioli G, et al. Fractures in relation to menstrual status and bone parameters in young athletes. Med Sci Sports Exerc 2015:47:1577-86.

51 Luedke LE, Heiderscheit BC, Williams DSB, et al. Influence of step rate on shin injury and anterior knee pain in high school runners. Med Sci Sports Exerc 2016:48:1244-50.

52 Timpka T, Jacobsson J, Dahlström Örjan, et al. The psychological factor 'self-blame' predicts overuse injury among top-level Swedish track and field athletes: a 12-month cohort study. Br J Sports Med 2015:49:1472-7.

53 Tenforde AS, Sayres LC, McCurdy ML, et al. Overuse injuries in high school runners: lifetime prevalence and prevention strategies. Pm R 2011;3:125-31.

54 Knapik JJ, Trone DW, Tchandja J, et al. Injury-reduction effectiveness of prescribing running shoes on the basis of foot arch height: summary of military investigations. J Orthop Sports Phys Ther 2014:44:805-12.

55 Theisen D, Malisoux L, Genin J, et al. Influence of midsole hardness of standard cushioned shoes on running-related injury risk. Br J Sports Med 2014:48:371-6.

56 van Gent RN, Siem D, van Middelkoop M, et al. Incidence and determinants of lower extremity running injuries in long distance runners: a systematic review. Br J Sports Med 2007;41:469-80.

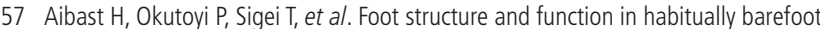
and Shod adolescents in Kenya. Curr Sports Med Rep 2017;16:448-58.

58 Lieberman DE, Venkadesan M, Werbel WA, et al. Foot strike patterns and collision forces in habitually barefoot versus shod runners. Nature 2010;463:531-5.

59 Lieberman DE, Castillo ER, Otarola-Castillo E, et al. Variation in foot strike patterns among habitually barefoot and Shod runners in Kenya. PLoS One 2015; 10:e0131354

60 Hollander K, Riebe D, Campe S, et al. Effects of footwear on treadmill running biomechanics in preadolescent children. Gait Posture 2014;40:381-5.

$61 \mathrm{Au} \mathrm{IPH}$, Lau FOY, An WW, et al. Immediate and short-term biomechanical adaptation of habitual barefoot runners who start shod running. J Sports SCi 2018:36:451-5

62 Hollander K, de Villiers J, Venter R, et al. Foot strike patterns differ between children and adolescents growing up barefoot vs. Shod. Int J Sports Med 2018;39:97-103.

63 McClean G, Riding NR, Ardern CL, et al. Electrical and structural adaptations of the paediatric athlete's heart: a systematic review with meta-analysis. Br J Sports Med 2018; $52: 230$

64 Churchill TW, Groezinger E, Loomer G, et al. Exercise-Induced cardiac remodeling during adolescence. Eur J Prev Cardiol 2019:2047487319869691.

65 Baggish AL, Yared K, Wang F, et al. The impact of endurance exercise training on left ventricular systolic mechanics. Am J Physiol Heart Circ Physiol 2008:295:H1109-16.

66 Wasfy MM, Weiner RB, Wang F, et al. Endurance exercise-induced cardiac remodeling: not all sports are created equal. J Am Soc Echocardiogr 2015;28:1434-40.

67 Roberts WO, Stovitz SD. Incidence of sudden cardiac death in Minnesota high school athletes 1993-2012 screened with a standardized pre-participation evaluation. J Am Coll Cardiol 2013;62:1298-301.

68 Endres BD, Kerr ZY, Stearns RL, et al. Epidemiology of sudden death in organized youth sports in the United States, 2007-2015. J Athl Train 2019;54:349-55. 
69 Harmon KG, Asif IM, Maleszewski JJ, et al. Incidence and etiology of sudden cardiac arrest and death in high school athletes in the United States. Mayo Clin Proc 2016;91:1493-502.

70 ACSM. Preparticipation physical evaluation. 5th Edn, 2019.

71 De Souza MJ, Nattiv A, Joy E, et al. 2014 female athlete triad coalition consensus statement on treatment and return to play of the female athlete triad: 1st International Conference held in San Francisco, California, may 2012 and 2nd International Conference held in Indianapolis, Indiana, may 2013. Br J Sports Med 2014;48:289.

72 Mountjoy M, Sundgot-Borgen J, Burke L, et al. RED-S cat. relative energy deficiency in sport (RED-S) clinical assessment tool (cat). Br J Sports Med 2015;49:421-3.

73 Mountjoy M, Sundgot-Borgen JK, Burke LM, et al. IOC consensus statement on relative energy deficiency in sport (RED-S): 2018 update. Br J Sports Med 2018; 52:687-97.

74 Williams EA, Pelto HF, Toresdahl BG, et al. Performance of the American heart association (AHA) 14-Point evaluation versus electrocardiography for the cardiovascular screening of high school athletes: a prospective study. J Am Heart Assoc 2019;8:e012235.

75 Maron BJ, Friedman RA, Kligfield P, et al. Assessment of the 12-lead ECG as a screening test for detection of cardiovascular disease in healthy general populations of young people (12-25 years of age): a scientific statement from the American heart association and the American College of cardiology. Circulation 2014;130:1303-34.

76 Adami PE, Squeo MR, Quattrini FM, et al. Pre-participation health evaluation in adolescent athletes competing at youth Olympic games: proposal for a tailored protocol. Br J Sports Med 2019;53:1111-6.

77 Fudge J, Harmon KG, Owens DS, et al. Cardiovascular screening in adolescents and young adults: a prospective study comparing the Pre-participation physical evaluation monograph 4th edition and ECG. Br J Sports Med 2014:48:1172-8.

78 Drezner JA, O'Connor FG, Harmon KG, et al. AMSSM position statement on cardiovascular Preparticipation screening in athletes: current evidence, knowledge gaps, recommendations and future directions. Br J Sports Med 2017;51:153-67.

79 Drezner JA, Sharma S, Baggish A, et al. International criteria for electrocardiographic interpretation in athletes: consensus statement. Br J Sports Med 2017;51:704-31.

80 Thomas DT, Erdman KA, Burke LM. Position of the Academy of nutrition and dietetics, dietitians of Canada, and the American College of sports medicine: nutrition and athletic performance. J Acad Nutr Diet 2016;116:501-28.

81 Barrack MT, Van Loan MD, Rauh MJ, et al. Physiologic and behavioral indicators of energy deficiency in female adolescent runners with elevated bone turnover. Am J Clin Nutr 2010:92:652-9.

82 Muia EN, Wright HH, Onywera VO, et al. Adolescent elite Kenyan runners are at risk for energy deficiency, menstrual dysfunction and disordered eating. J Sports Sci 2016;34:598-606.

83 Iwasaki Y, Miyahara K, Miyatake N, et al. Thyroid function decline and diet in female high school long-distance runners. Acta Med Okayama 2019;73:127-33.

84 Wiita BG, Stombaugh IA. Nutrition knowledge, eating practices, and health of adolescent female runners: a 3-year longitudinal study. Int I Sport Nutr 1996;6:414-25.

85 Eisenmann JC, Wickel EE. Estimated energy expenditure and physical activity patterns of adolescent distance runners. Int I Sport Nutr Exerc Metab 2007:17:178-88

86 Io M. Dietary reference intakes for energy, carbohydrate, fiber, fat, fatty acids, cholesterol, protein, and amino acids. Washington, DC: The National Academies Press, 2005.

87 Burdette HL, Whitaker RC. Resurrecting free play in young children: looking beyond fitness and fatness to attention, affiliation, and affect. Arch Pediatr Adolesc Med 2005; 159:46-50
88 Larouche R, Blanchette S, Faulkner G, et al. Correlates of children's physical activity: a Canadian multisite study. Med Sci Sports Exerc 2019:51:2482-90.

89 Myer GD, Jayanthi N, Difiori JP, et al. Sport specialization, part I: does early sports specialization increase negative outcomes and reduce the opportunity for success in young athletes? Sports Health 2015;7:437-42.

90 Lubans DR, Morgan PJ, Cliff DP, et al. Fundamental movement skills in children and adolescents: review of associated health benefits. Sports Med 2010;40:1019-35.

91 Kriemler S, Zahner L, Schindler C, et al. Effect of school based physical activity programme (kiss) on fitness and adiposity in primary schoolchildren: cluster randomised controlled trial. BMJ 2010;340:c785.

92 Services UDoHaH. 2018 physical activity guidelines Advisory Committee scientific report, 2018.

93 WHO. Global recommendations on physical activity for health. Available: https:// www.who.int/dietphysicalactivity/publications/9789241599979/en/Available from: files/171/en.html

94 Finley PS, Fountain JS, Finley DP. Road racing and youth running: cross country coaches' perspectives. The Sport Journal 2017.

95 Jenny S, Armstrong T. Distance running and the Elementary-age child. J Phys Educ Recreat Dance 2013:84:17-25.

96 Blankson KL, Brenner JS. Anticipatory guidance for long-distance running in young athletes. Pediatr Ann 2016:45:e83-6.

97 Students run La. Available: https://www.srla.org [Accessed 15 Jun 2019].

98 Miller EM GJ, Beck J, Runestad S, et al. Is marathon training safe for adolescents? AMSSM research Podium presentations. Clin J Sport Med 2018:28:239-48.

99 DiFiori JP, Benjamin HJ, Brenner JS, et al. Overuse injuries and burnout in youth sports: a position statement from the American medical Society for sports medicine. Br J Sports Med 2014;48:287-8.

100 LaPrade RF, Agel J, Baker J, et al. AOSSM early sport specialization consensus statement. Orthop J Sports Med 2016;4:232596711664424.

101 Hall R, Barber Foss K, Hewett TE, et al. Sport specialization's association with an increased risk of developing anterior knee pain in adolescent female athletes. J Sport Rehabil 2015:24:31-5

102 Jayanthi NA, LaBella CR, Fischer D, et al. Sports-specialized intensive training and the risk of injury in young athletes: a clinical case-control study. Am J Sports Med 2015:43:794-801.

103 McGuine TA, Post EG, Hetzel SJ, et al. A prospective study on the effect of sport specialization on lower extremity injury rates in high school athletes. Am J Sports Med 2017;45:2706-12.

104 Post EG, Bell DR, Trigsted SM, et al. Association of competition volume, Club sports, and sport specialization with sex and lower extremity injury history in high school athletes. Sports Health 2017:9:518-23.

105 Post EG, Trigsted SM, Riekena JW, et al. The association of sport specialization and training volume with injury history in youth athletes. Am J Sports Med 2017:45:1405-12.

106 Rauh MJ, Tenforde AS, Barrack MT, et al. Associations between sport specialization Running-Related injury, and menstrual dysfunction among high school distance runners. Athl Train Sports Health Care 2018;10:260-9.

107 Miller EM BJ, Runestad S, Vo S, et al. Concurrent sports participation and prior marathon experience are not risk factors for injury in adolescent marathon runners: 2020 AMSSM rising with research presentations. Clin J Sport Med 2020;30:172-80.

108 Coleman E, Rosenbloom C. Sports Nutrition : A Practice Manual for Professionals. Chicago: Academy of Nutrition and Dietetics, 2012.

109 Barrack MT, Rauh MJ, Nichols JF. Cross-Sectional evidence of suppressed bone mineral accrual among female adolescent runners. J Bone Miner Res 2010;25:1850-7 